\title{
Multidrug Resistance Gene-1 Polymorphisms and Resistance to Cyclosporine A in Patients with Steroid Resistant Ulcerative Colitis
}

Fady Daniel, MD, ${ }^{*}$ Marie-Anne Loriot, MD, ${ }^{\dagger}$ Philippe Seksik, MD ${ }^{\ddagger}$ Jacques Cosnes, MD, PhD ${ }^{\ddagger}$ Jean-Marc Gornet, MD, ${ }^{\S}$ Marc Lémann, MD, PhD, ${ }^{\S}$ Francine Fein, MD,${ }^{\|}$Gwenola Vernier-Massouille, MD, ${ }^{\natural}$ Martine De Vos, MD, PhD, ${ }^{\#}$ Arnaud Boureille, MD, ${ }^{* *}$ Xavier Treton, MD ${ }^{\dagger \dagger}$ Bernard Flourié, MD, PhD, ${ }^{\ddagger}$ Xavier Roblin, $\mathrm{MD}, \mathrm{PhD},{ }^{\S \S}$ Edouard Louis, MD, PhD, ${ }^{|| l \mid}$ Frank Zerbib, MD, PhD, ${ }^{\text {१ף }}$ Philippe Beaune, MD, PhD, ${ }^{\dagger}$ Philippe Marteau, MD, PhD, ${ }^{\# \#}$ and the GETAID

*Department of Gastroenterology, Assistance publique des hôpitaux de Paris (AP-HP), Hôpital Européen Georges Pompidou, Paris, France †Department of Biochemistry, AP-HP, Hôpital Européen Georges Pompidou, Université René Descartes, faculté de Médecine and INSERM UMRS-775, Paris, France

†P-HP, Hôpital Saint-Antoine, Paris, France

$\S$ Department of Gastroenterology, AP-HP, Hôpital Saint-Louis, Paris, France

||Department of Gastroenterology, Hôpital Jean Minjoz, Besançon, France

|Department of Gastroenterology, Hôpital Claude Huriez, Lille, France

\#Department of Gastroenterology, CHU de Gent, Gent, Belgium

**Department of Gastroenterology, Hôpital Hôtel Dieu, Nantes, France

†Department of Gastroenterology, AP-HP, Hôpital Beaujon, Clichy, France

t+Department of Gastroenterology, CHU Lyon Sud, Lyon, France

$\S \S$ Department of Gastroenterology, CHU de Grenoble, Grenoble, France

||||Department of "Gastroenterology, CHU de Liège, Liège, Belgium

qDepartment of Gastroenterology, Hôpital Saint André, Bordeaux, France

\#Department of Gastroenterology, AP-HP, Hôpital Lariboisière, Paris, France

Background : Cyclosporine A (CsA) is inconstantly effective in inducing remission in acute attacks of ulcerative colitis (UC) not responding to steroids.. This study aimed to establish whether multidrug resistance gene (MDR)1 polymorphisms would be associated with CsA failure.

Patients and Methods : The distribution of the different genotypes of single nucleotide polymorphisms (SNP) G2677T/A and C3435T of MDR1 exons 21 and 26, respectively, was studied in 154 patients (mean age, 44 yr) who had received CsA to treat severe attacks of steroid resistant UC in 11 centers in France and Belgium. Patients were classified as CsA failure $(n=50)$ when they needed colectomy within 30 days after CsA initiation. The SNPs were detected by use of a 5 ' nuclease allelic discrimination assay.

Results : There was a significant association between the G2677T/A polymorphism distribution (exon 21) and the risk for CsA failure $(P=0.0001)$. The TT genotype of exon. 21 was significantly associated with the risk compared with the two other genotypes (odds ratio, 3.77; 95\% confidence interval, 1.42-9.97, $P=0.007$ ). There was no significant association between the genotype $\mathrm{C} 3435 \mathrm{~T}$ distribution (exon 26) and the risk of CsA failure $(P=0.23)$.

Conclusion : The TT genotype of exon 21 MDR1 polymorphisms is associated with a higher risk of CsA failure in patients with steroid resistant UC. Further studies should be performed to establish whether other treatments could be more efficient to avoid surgery in this subset of patients.

Keywords : ulcerative colitis ; cyclosporine ; multidrug resistance gene-1.

Severe attacks of ulcerative colitis (UC) are a life-threatening condition, and the first line treatment relies on high doses of corticosteroids. ${ }^{1,2}$ Cyclosporine A (CsA) has been shown to be effective to avoid early colectomy in 
approximately two thirds of the patients with steroid resistance ${ }^{3}$ however, this drug has potential risks including renal insufficiency, hypertension, and opportunistic infections. ${ }^{4}$ Infliximab has recently been shown to be also effective in this setting. ${ }^{5}$ Finding predictors for efficacy or failure of these drugs may certainly help the clinician to make treatment decisions.

The metabolism of CsA has a high inter-individual variability. ${ }^{6} \mathrm{CsA}$ is a substrate of P-glycoprotein (P-gp), a transporter expressed at the surface of epithelial and lymphoid cells that is encoded by the multidrug resistance gene (MDR)1. Single nucleotide polymorphisms (SNP) have been found in various regions of the MDR1 gene. They include SNP G2677T/A in exon 21 and SNP C3435T in exon 26. ${ }^{7}$ It has been suggested that the TT genotype of C3435T SNP is a predisposing factor for UC, extensive lesions, ${ }^{8-10}$ and a higher risk of colectomy. ${ }^{11}$ A recent study searched for correlations between the MDR1 polymorphisms and drug resistance in IBD; however, the statistical power was too low to exclude any correlation with CsA efficacy because only 11 patients of this series had received this drug. ${ }^{12}$

To test the hypothesis that MDR1 polymorphisms would be predictive of CsA resistance in patients with severe attacks of steroid resistant UC, we compared the distribution of the different SNPs of MDR1 exons 21 and 26 in a large series of patients presenting with steroid resistant severe UC necessitating CsA therapy and who were classified as responded or resistant to CsA on the basis of the need of colectomy within the 30 days after CsA initiation.

\section{PATIENTS AND METHODS}

This study was performed in 11 IBD clinics of the GETAID (Groupe d'Etudes Thérapeutiques des Affections Inflammatoires Digestives) in France and Belgium. Patients who had been treated by CsA for severe steroid resistant UC were retrospectively identified. Inclusion criteria were a past history of an acute steroid resistant flair of UC requiring CsA rescue therapy $(2-4 \mathrm{mg} / \mathrm{kg} / \mathrm{d})$ and a follow-up after CsA. Patients with Crohn's disease and indeterminate colitis were excluded. CsA failure was defined as the need for colectomy within 30 days after the start of CsA. Patients who were not colectomized within the first 30 days were considered as "responders." We collected information on the disease extent, duration of UC and of the present flare, smoking, as well as the number of bloody stools per day, and C-reactive protein (CRP), which have been previously shown to be associated with the risk of colectomy. ${ }^{13}$

The methods used to monitor CsA blood levels differed between centers, so the results could not be pooled. Thirty-two patients from a single institution had a similar monitoring (EMIT 2000 cyclosporine assay, DadeBehring, Roche CO-BAS Mira, Liederbach, Germany). Correlations between the blood CsA level, CsA doses, the risk for colectomy, and the MDR1 genotypes were studied in this subgroup of patients.

Blood samples were collected for genotyping after obtaining a written informed consent by the patients. Genotyping was performed using Taqman method. The SNPs of MDR1 exon 21 and exon $26(3435 \mathrm{C}>\mathrm{T})$ were detected by use of a 5' nuclease allelic Discrimination assay (ABI PRISM 7700 Sequence Detection System; Applied Biosystems, Foster City, CA). The sequences of the primers and specific probes were labeled with the fluorescent reporter dyes FAM and VIC at their 5' extremities. The MDR1 SNPs and two-locus haplotype associations were studied as previously described. ${ }^{14,15}$

\section{Statistical Analysis}

Quantitative variables were expressed as mean \pm standard deviation. Statistical analysis was performed using Stat-view 5.0 software for Windows (SAS Institute, Inc., 1992-1998, Cary, NC). Distributions of qualitative variables were compared between groups by the chi-square test; distributions of quantitative parameters were compared between groups by parametric or nonparametric tests depending on the normality of the variables tested (Wilks-Shapiro test). Results were expressed with odds ratio (OR) and 95\% confidence intervals (95\% $\mathrm{CI})$. For each analysis, $P$ values less than 0.05 were considered to be statistically significant. All variables with a $P$ value less than 0.20 on univariate analysis were included in a logistic regression model to determine ORs for CsA resistance. The goodness of fit was verified by the Hosmer-Lemshow test.

\section{RESULTS}

One hundred fifty-four patients responding to the inclusion criteria participated in the study. Their characteristics are summarized in Table 1. Fifty-five (33\%) patients were colectomized within the first 30 days after CsA initiation. CsA failure patients did not differ from CsA responders for age, sex, disease extent or duration, and 
smoking history (Table 1). Data for genotyping of exons 21 and 26 were finally available for 150 and 153 patients, respectively. The mean duration intravenous CsA use was 8 (range, 1-23) days and 103 (range, 6-684) days for oral CsA.

Allele and genotype frequencies in the different groups are shown in Tables 2 and 3. The distribution of MDR polymorphism were in close agreement with that predicted by the Hardy Weinberg equilibrium $\left(\chi^{2}=0.27, P=\right.$ 0.80 for exon 21 and $\chi^{2}=0.19, P=0.43$ for exon 26$)$. There was a significant association between the G2677T/A polymorphism distribution and the risk of CsA failure $(P=0.0001)$ (Table 2$)$. The TT genotype of exon 21 was significantly associated with the risk of CsA failure compared with the other genotypes (OR, 3.77; 95\% CI, 1.42-9.97; $P=0.007)$. There was no significant association between the genotype C3435T distribution (exon 26) and the risk of CsA failure $(\mathrm{P}=0.23)$ as well as for the TT genotype of exon $26(\mathrm{OR}, 1.58 ; 95 \% \mathrm{CI}$, $0.72-3.46, P=0.25$ ) (Table 3 ). No statistically significant difference was found in two-locus haplotype distribution between CsA resistant patients and responders (data not shown).

TABLE 1: Characteristics of Patients

\begin{tabular}{lccc}
\hline & $\begin{array}{c}\text { Total, } \\
\mathbf{n}=\mathbf{1 5 4}\end{array}$ & $\begin{array}{c}\text { CsA } \\
\text { Resistant, } \\
\mathbf{n = 5 0}\end{array}$ & $\begin{array}{c}\text { CsA } \\
\text { Responders, } \\
\mathbf{n = 1 0 4}\end{array}$ \\
\hline Age in years, mean (SD) & $44.4(14.4)$ & $45.8(15.7)$ & $43.5(13.9)$ \\
Male (\%) & 54 & 48 & 57 \\
Disease extent (\%) & & & \\
$\quad$ Distal & 3 & 0 & 3 \\
$\quad$ Left colon & 17 & 12 & 20 \\
$\quad$ Pancolitis & 80 & 88 & 77 \\
Disease duration in months, mean (range) & $63(0-367)$ & $77(0-223)$ & $57(45-367)$ \\
Flare duration in days, mean (range) & $47(5-223)$ & $54(6-57)$ & $44(5-78)$ \\
Smoking status (\%) & & & \\
$\quad$ Never & 65 & 60 & 65 \\
$\quad$ Ex-smokers & 28 & 30 & 29 \\
$\quad$ Smokers & 7 & 10 & 6 \\
\hline CsA & & & \\
\hline
\end{tabular}

$\mathrm{CsA}=$ cyclosporine $\mathrm{A} ; \mathrm{SD}=$ standard deviation.

TABLE 2: Genotype Frequencies of SNP G2677T/A (exon 21) in Different Groups of Patients

\begin{tabular}{llll}
\hline & CsA & CsA & Total \\
& Resistant & Responders & \\
\hline No. & 49 & 101 & 150 \\
Allele frequency G (\%) & 54.6 & 63.3 & 62.3 \\
Allele frequency T (\%) & 45.4 & 36.7 & 37.7 \\
GG (\%) & 44.9 & 34.3 & 38 \\
GT or GA* (\%) & 30.6 & 57.8 & 48.7 \\
TT* (\%) & 24.5 & 7.9 & 13.3 \\
\hline
\end{tabular}

${ }^{*}$ Genotyping was feasible in 150 patients; only 5 patients had the GA genotype, no AA or TA genotypes; GA and GT were considered as one group. $\mathrm{CsA}=$ cyclosporine $\mathrm{A}$.

TABLE 3: Genotype Frequencies of SNP C3435T (exon 26) in Different Groups of Patients

\begin{tabular}{llll}
\hline & CsA & CsA & Total \\
& Resistant & Responders & \\
\hline No. & 49 & 104 & 153 \\
Allele frequency C (\%) & 53.1 & 53.3 & 53.3 \\
Allele frequency T (\%) & 46.9 & 46.7 & 46.7 \\
CC (\%) & 34.6 & 26.7 & 29.4
\end{tabular}




\begin{tabular}{llll} 
CT (\%) & 36.7 & 53.3 & 47.7 \\
TT(\%) & 28.7 & 20 & 22.9 \\
\hline
\end{tabular}

CsA $=$ cyclosporine $\mathrm{A}$

\section{Variables Predictive of CsA Failure}

With sue of univariate analysis, CsA resistant had, in comparison with patients responsive to CsA therapy, higher CRP level $(76.4 \pm 8.5 \mathrm{mg} / \mathrm{L}$ vs. $53.4 \pm 4.5 ; P=0.001)$ and higher number of bloody stools $(10.0 \pm 4.5 \mathrm{vs}$ $8.3 \pm 3.0 ; P=0.01)$ at baseline. In multivariate analysis, CRP levels (OR, 1.008; 95\% CI, 1.001-1.0017; $P=$ $0.04)$, the number of bloody stools (OR, $1.12 ; 95 \% \mathrm{CI}, 1.004-1.251 ; P=0.04)$, and exon 21 genotype TT (OR, $6.75 ; 95 \% \mathrm{CI}, 1.53-29.71 ; P=0.01)$ remained significantly and independently predictive of response to CsA.

\section{Genotypes and CsA Doses and Blood Concentrations}

In the 32 patients from a single institution who had the same protocol to measure blood CsA levels, $16(50 \%)$ patients needed early colectomy. No significant difference was found in this subgroup in terms of mean CsA daily dose, CsA weight adjusted dose, and mean CsA blood level between the CsA resistant and responders and neither between the various genotypes of exons 21 and 26 (Table 4). However, during treatment, the CsA dose tended to be adjusted differently according to the exon 21 genotype (Wilcoxon rank sum test, $P=0.08$ ). The CsA dose was decreased in only 1 patient of 7 with the TT genotype versus 12 of 24 patients with other exon 21 genotypes. Concomitantly, the mean blood CsA level remained stable in genotype TT patients (from $289 \pm 146$ to $291 \pm 77 \mathrm{ng} / \mathrm{mL}$ ), whereas it decreased in the patients with other exon 21 genotypes (from $281 \pm 83$ to $229 \pm$ $100 \mathrm{ng} / \mathrm{mL}, P=0.07)$. In other terms, the lack of response to CsA observed in patients with the exon 21 genotype TT was not the consequence of an insufficient CsA dose but was observed in spite of an increasing CsA dose.

TABLE 4: Comparison of CSA Doses and Serum Concentrations According to Different Genotypes of SNPS C3435T (Exon 26) and G2677T/A (Exon 21) $(n=32)$

\begin{tabular}{|c|c|c|c|c|c|c|c|c|}
\hline & \multicolumn{4}{|c|}{ MDR1 Exon 26} & \multicolumn{4}{|c|}{ MDR1 Exon 21} \\
\hline & $\mathrm{CC}$ & CT & TT & & GG & GT & TT & \\
\hline Serum CsA concentration, $\mathrm{ng} / \mathrm{mL}$ & $264.0(31.9)$ & $261.1(22.3)$ & $328.7(39.1)$ & NS & $272.4(20.8)$ & $258.2(16.8)$ & $302.1(40.2)$ & NS \\
\hline IV CsA dose, mg/d & $126.2(10.7)$ & $137.7(19.6)$ & $139.3(13.4)$ & NS & $136.8(21.0)$ & $128.8(16.2)$ & $144.3(13.6)$ & NS \\
\hline IV CsA dose/body weight, $\mathrm{mg} / \mathrm{kg} / \mathrm{d}$ & $2.0(0.1)$ & $2.23(0.3)$ & $2.29(0.2)$ & NS & $2.0(0.1)$ & $2.23(0.3)$ & $2.29(0.2)$ & NS \\
\hline
\end{tabular}

Results are expressed as means (standard deviation). CsA = cyclosporine A; IV = intravenous.

\section{DISCUSSION}

The present study shows a significant association between MDR1 polymorphism and the resistance to CsA in patients presenting with steroid resistant UC. Namely, the polymorphisms of G2677T/A in exon 21 SNP, and especially the TT genotype, were significantly associated with an increased risk of resistance to CsA. The frequency of the genotypes of exons 21 and 26 SNPs of the MDR1 gene in our cohort was consistent with previous studies. ${ }^{16,17}$

CsA is a substrate of P-gp encoded by the MDR1 gene and presents high interindividual pharmacokinetic variability. The MDR1 gene has been shown so far to play a role in determining disease susceptibility and disease behavior in IBD. The hypothesis that altered P-gp expression in IBD patients could modify the response to medical therapy was assessed by Farrell et al. ${ }^{18}$ Peripheral blood lymphocytes from patients with UC or Crohn's disease with previous bowel resection for medical treatment failure had a higher P-gp expression compared with patients with inactive disease. In contrast, Langman et al ${ }^{19}$ reported that MDR1 gene expression was down-regulated in colonic tissue of UC patients. Several studies have suggested that the TT genotype of C3435T SNP in exon 26 is a predisposing factor to UC, with pan colonic involvement, ${ }^{8-10}$ and could predict the need for colectomy. ${ }^{11}$ These studies did not look at potential correlations between these markers and the resistance to CsA. Recently, Palmieri et al $^{12}$ found that MDR1 polymorphisms had no significant role in disease 
susceptibility and response to medical therapy in their Italian population of inflammatory bowel disease patients. Nevertheless, there were only 11 patients treated by CsA. Two other large population-based case-control studies failed to show a significant association between C3435T MDR1 gene polymorphism and predisposition to UC. ${ }^{20,21}$ but did not assess response to treatment. Our study, which included a large number of patients treated with CsA, identified genotype TT of exon 21 as a powerful predictor of CsA failure, whereas the TT genotype of exon 26 was not predictive. The role of exon $26 \mathrm{C} 3435 \mathrm{~T}$ on CsA pharmacokinetics has been controversial in the literature. Several studies found no correlation between these two parameters in renal transplant recipients, ${ }^{22-26}$ but a recent study found that exon $26 \mathrm{C} 3435 \mathrm{~T}$ influenced the dose of CsA to be administered to achieve the target concentration in the serum of liver transplant recipients. ${ }^{27} \mathrm{We}$ found no significant correlation between the C3435T and G2677T/A polymorphism and the CsA levels or the CsA dose; however, the subset of patients for whom CsA dosages were available for correlation analysis was limited $(n=32)$.

There is controversy regarding the effects of polymorphism G2677T/A on MDR1 transport activities. This polymorphism could be in linkage disequilibrium, with a polymorphism elsewhere in the genome that modifies $M D R 1$ expression or function. ${ }^{7}$ Some evidence linking this polymorphism to IBD susceptibility already exists. Brant et $\mathrm{al}^{28}$ found a significant association of the Ala893 variant (G2677) of the tri-allelic G2677T/A SNP (Ala893Ser/Thr) of exon 21, known to decrease transporter function, with Crohn's disease; a nonsignificant trend was also found in UC patients. Likewise, an association with the T allele (893Ser variant) of exon 21 was found in UC patients by Potocnik et al. ${ }^{29}$ Two intronic SNPs in linkage disequilibrium with exons 21 and 26 haplotype, one in intron 13 (rs2235035) and another in intron 16 (rs1922242), were significantly associated with refractory Crohn's disease $(P=0.026$, OR, 2.7 and $P=0.025$, OR 2.8 , respectively), as well as with $\mathrm{UC}(P=$ 0.006 , OR 1.8 and $P=0.026$, OR 1.9 , respectively). Ho et al $^{9}$ did not find an association between G2677T/A SNP polymorphism and IBD; however, a two-locus haplotype (3435T/G2677) was significantly associated with UC in their study. They reported a nonsignificant increase in the frequency of exon 26 TT genotype in UC patients requiring colectomy (as also noticed in our series).

The classical pharmacogenetic model whereby high MDR1 expression may mediate drug resistance in IBD appears countered by the fact that low $M D R 1$ expression could be associated with increased susceptibility to IBD. Sambuelli et $\mathrm{al}^{30}$ found a high expression of P-gp in the mucosa of patients with refractory UC. In addition, a recent study suggested that MDR1 genotypes determine early onset and severe course of disease in UC. ${ }^{31}$ The finding that mdrla-knockout mice develop a UC-like colitis that can be prevented by antibiotics suggests that Pgp-170 may have a defensive barrier function against microbial products or components. ${ }^{7}$ Our study was designed to establish whether MDR1 polymorphisms could help predict CsA response in UC patients failing steroids but not to search for a possible role in disease susceptibility because it did not include a control group of normal patients.

Using logistic regression analysis, we identified the number of bloody stools, CRP level, and exon 21 TT genotype as independent predictive variables of therapeutic response to CsA. CRP level and the number of stools have already been described as predictors of a high risk for surgery in patients with severe UC treated with steroids, ${ }^{12}$ and physicians probably largely use these criteria to make treatment decisions. Interestingly, the OR associated with exon 21 TT genotype was far greater than those associated with CRP and number of bloody stools, underscoring perhaps its positive predictive value in estimating the risk of CsA failure. Moreover, no significant statistical interaction was found between this genotype and CRP or number of bloody stools.

In conclusion, our preliminary study supports the hypothesis that exon 21 polymorphisms of MDR1 gene may be considered as predictors of response to medical therapy in patients with acute steroid resistant UC and who receive CsA. Further studies with larger adequate sample size should be performed to establish whether they can help in making difficult treatment decisions, especially in choosing among surgery, CsA, and infliximab.

\section{ACKNOWLEDGMENTS}

The authors thank Dr. Isabelle Etienney for her statistical input, David-Alexandre Tregouet for helpful assistance in haplotype analysis, and Jack Satsangi and Gwo-tzer Ho for their comments during the preparation of the paper.

The study was supported by a grant from Ferring laboratories, France.

Ferring laboratories had no involvement in study design, analysis, interpretation of data, writing of the report, or decision to submit the paper for publication. 
Published in: Inflammatory Bowel Disease (2007), vol.13, pp.19-23

Status: Postprint (Author's version)

\section{REFERENCES}

1. Carter MJ, Lobo AJ, Travis SP, and DBD Section, British Society of Gastroenterology. Guidelines for the management of inflammatory bowel disease in adults. Gut. 2004;53(Suppl 5):V1-V16.

2. Marteau P, Seksik P, Beaugerie L, et al. Recommendations for clinical practice for the treatment of ulcerative colitis. Gastroenterol Clin Biol. 2004;28:955-960.

3. Lichtiger S, Present DH, Kornbluth A, et al. Cyclosporine in severe ulcerative colitis refractory to steroid therapy. $N$ Engl $J$ Med. 1994;330: 1841-1845.

4. Arts J, D'Haens G, Zeegers M, et al. Long-term outcome of treatment with intravenous cyclosporin in patients with severe ulcerative colitis. Inflamm Bowel Dis. 2004;10:73-78.

5. Jamerot G, Hertervig E, Friis-Liby I, et al. Infliximab as rescue therapy in severe to moderately severe ulcerative colitis: a randomized, placebo-controlled study. Gastroenterology. 2005;28:1805-1811.

6. Saeki T, Ueda K, Tanigawara Y, et al. Human P-glycoprotein transports cyclosporin A and FK 506. J Biol Chem. 1993;268:6077.

7. Schwab M, Eichelbaum M, Fromm MF. Genetic polymorphisms of the human MDR1 drug transporter. Annu Rev Pharmacol Toxicol 2003;43: 285-307.

8. Schwab M, Schaeffeler E, Marx C, et al. Association between the 3435T MDR1 gene polymorphism and susceptibility for ulcerative colitis. Gastroenterology. 2003;124:26-33.

9. Ho GT, Nimmo ER, Tenesa A, et al. Allelic variations of the multidrug resistance gene (MDR1) determine susceptibility and disease behaviour in ulcerative colitis. Gastroenterology. 2005;128:288-296.

10. McGovern D, Ahmad T, Van Heel D, et al. A genetic panel strongly predicts the need for colectomy in ulcerative colitis. Gastroenterology. 2004;26:A525.

11. Palmieri O, Latiano A, Valvano R, et al. Multidrug resistance 1 gene polymorphisms are not associated with inflammatory bowel disease and response to therapy in Italian patients. Aliment Pharmacol Ther. 2005; 22:1129-1138.

12. Travis SP. Review article: the management of mild to severe acute ulcerative colitis. Aliment Pharmacol Ther. 2004;20(Suppl 4):88-92.

13. Anglicheau D, Verstuyft C, Laurent-Puig P, et al. Association of the multidrug resistance-1 gene single-nucleotide polymorphisms with the tacrolimus dose requirements in renal transplant recipients. J Am Soc Nephrol. 2003;14:1889-1896.

14. Hoffmeyer S, Burk O, von Richter O, et al. Functional polymorphisms of the human multidrug-resistance gene: multiple sequence variations and correlation of one allele with P-glycoprotein expression and activity in vivo. Proc Natl Acad Sci USA. 2000;97:3473-3478.

15. Bernai ML, Sinues B, Fanlo A, et al. Frequency distribution of C3435T mutation in exon 26 of the MDR 1 gene in a Spanish population. Ther Drug Monit. 2003;25:107.

16. Farrell RJ, Murphy A, Long A, et al. High multidrug resistance (P-glycoprotein 170) expression in inflammatory bowel disease patients who fail medical therapy. Gastroenterology. 2000;118:279-288.

17. Langmann T, Moehle C, Mauerer R, et al. Loss of detoxification in inflammatory bowel disease: dysregulation of pregnane X receptor target genes. Gastroenterology. 2004;127:26-40.

18. Gazouli M, Zacharatos P, Gorgoulis V, et al. The C3435T MDR1 gene polymorphism is not associated with susceptibility for ulcerative colitis in Greek population. Gastroenterology. 2004;126:367-369.

19. Croucher PJ, Mascheretti S, Foelsch UR, et al. Lack of association between the C3435T MDR1 gene polymorphism and inflammatory bowel disease in two independent Northern European populations. Gastroenterology. 2003;125:1919-1920.

20. Hesselink DA, Van Schaik RH, Van der Heiden IP, et al. Genetic polymorphisms of the CYP3A4, CYP3A5, and MDR1 genes and phar. macokinetics of the calcineurin inhibitors cyclosporine and tacrolimus. Clin Pharmacol Ther. 2003;74:245-254.

21. Yates CR, Zhang W, Song P, et al. The effect of CYP3A5 and MDR1 polymorphic expression on cyclosporine oral disposition in renal transplant patients. J Clin Pharmacol. 2003;43:555-564.

22. Von Ahsen N, Richter M, Grupp C, et al. No influence of the MDR1 C3435T polymorphism or a CYP3A4 promoter polymorphism (CYP3A4-V allele) on dose-adjusted cyclosporin A trough concentrations or rejection incidence in stable renal transplant recipients. Clin Chem. 2001;47:1048-1052.

23. Mai I, Stormer E, Goldammer M, et al. MDR1 haplotypes do not affect the steady-state pharmacokinetics of cyclosporine in renal 
Published in: Inflammatory Bowel Disease (2007), vol.13, pp.19-23

Status: Postprint (Author's version)

transplant patients. J Clin Pharmacol. 2003;43:1101-1107.

24. Hesselink DA, van Gelder T, van Schaik RH, et al. Population pharmacokinetics of cyclosporine in kidney and heart transplant recipients and the influence of ethnicity and genetic polymorphisms in the MDR1, CYP3A4, and CYP3A5 genes. Clin Pharmacol Ther. 2004;76:545-556.

25. Bonhomme-Faivre L, Devocelle A, Saliba F, et al. MDR1 C3435T polymorphism influences cyclosporine a dose requirement in livertransplant recipients. Transplantation. 2004;78:21-25.

26. Brant SR, Panhuysen CI, Nicolae D, et al. MDR1 Ala893 polymorphism is associated with inflammatory bowel disease. Am J Hum Genet. 2003; 73:1282-1292.

27. Potocnik U, Ferkolj I, Glavac D, et al. Polymorphisms in multidrug resistance 1 (MDR1) gene are associated with refractory Crohn disease and ulcerative colitis. Genes Immun. 2004;5:530-539.

28. Sambuelli A, Negreira S, Gil A, et al. Multidrug resistance Gene (MDR1) expression in intestinal mucosa of patients with refractory ulcerative colitis [Abstract]. Gastroenterology. 2005;28:A-156.

29. Fiedler T, Buening C, Reuter W, et al. Mdr1 genotypes determine early onset and severe course of disease in ulcerative colitis [Abstract T1026]. Gastroenterology. 2005.

30. Sambuelli A, Negreira S, Gil A, et al. Multidrug resistance gene (MDR1) expression in intestinal mucosa of patients with refractory ulcerative colitis [Abstract]. Gastroenterology. 2005;28:A-156.

31. Fiedler T, Buening C, Reuter W, et al. Mdr1 genotypes determine early onset and severe course of disease in ulcerative colitis. Gastroenterology. 2005;28:[Abstract T1026]. 